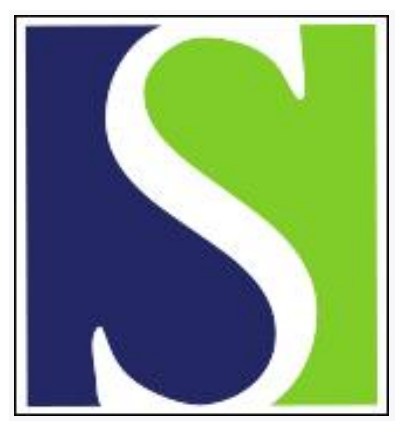

Scand J Work Environ Health 2003;29(1):15-21

https://doi.org/10.5271/sjweh.699

Issue date: Feb 2003

Influence of lack of full-time employment on attempted suicide in Manitoba, Canada

by Kraut A, Walld $R$

Affiliation: Department of Community Health Sciences, University of Manitoba, S112-750 Bannatyne Avenue, Winnipeg, Manitoba R3E OW3, Canada. akraut@ms.umanitoba.ca

Refers to the following texts of the Journal: 1999;25(1):42-49

2000;26(2):169-177

The following articles refer to this text: 2014;40(5):465-472;

2017;43(5):457-464

Key terms: attempted suicide; Canada; epidemiology; full-time employment; laborforce participation; mental health; part-time work; underemployment; unemployment

This article in PubMed: www.ncbi.nlm.nih.gov/pubmed/12630431

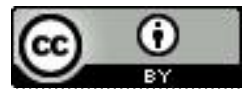




\section{Influence of lack of full-time employment on attempted suicide in Manitoba, Canada}

by Allen Kraut, MD, ${ }^{1,2}$ Randy Walld, BSc ${ }^{2,3}$

Kraut A, Walld R. Influence of lack of full-time employment on attempted suicide in Manitoba, Canada. Scand J Work Environ Health 2003;29(1):15-21.

Objectives Unemployment has been repeatedly associated with suicide; however, whether the association is causal remains unclear. Little is known about the relationship between part-time work and either attempted or completed suicide. The objective of this study was to compare the relationships of unemployment, part-time work, nonlaborforce participation, and full-time work with attempted suicide.

Methods This study utilized a database consisting of 27446 potential laborforce participants that combines information on health care utilization in Manitoba, Canada, with detailed information from the 1986 census. Persons who attempted suicide after the census $(\mathrm{N}=144)$ were identified using established definitions based on hospital claims to identify serious attempts only.

Results Step-wise multiple logistic regression, which controlled for multiple confounding variables, revealed that unemployment [odds ratio (OR) 3.68, 95\% confidence interval (95\% CI) 1.76-7.71, part-time work (OR $1.99,95 \%$ CI 1.07-3.71) and being out of the labor force (OR 2.11, 95\% CI 1.12-3.97)] were all associated with attempted suicide. A dose-response relationship was observed between weeks worked in 1985 and suicide attempts after the census.

Conclusions All three groups of those who were not working full-time had an elevated likelihood of attempted suicide after adjustment for potential confounding factors This finding suggests that working full-time is protective against suicide attempts. Suicide attempts related to lack of full-time work may be more preventable than other causes of attempted suicide and may be decreased by social policies that limit "under" and unemployment.

Key terms epidemiology, laborforce participation, mental health, part-time work, underemployment, unemployment.

Although suicide accounts for only about $2 \%$ of the deaths in Canada, it is a major cause of death among working-age adults, accounting for almost $11 \%$ of the total potential years of life lost (1). Mortality data underestimate the true effects of attempted suicide as they do not consider the large number of unsuccessful attempts and their associated human and financial costs. Unemployment has been repeatedly associated with suicide; however, whether the association is causal remains unclear (2-9). The two competing mechanisms, causation and selection, may explain this association.
Unemployment may precipitate suicide attempts through a combination of effects arising from loss of income (10), increases in unhealthy life-styles (11), loss of selfesteem (12), and psychological distress $(13,14)$. However, selection, where background and other personal characteristics, place persons simultaneously at higher risk for both unemployment and poor mental health (7, 15-19), might also explain the association.

Official unemployment rates only include persons who are not working and are actively seeking work. Official rates underestimate the true extent of

1 Department of Internal Medicine, Winnipeg, Manitoba, Canada.

2 Department of Community Health Sciences, Winnipeg, Manitoba, Canada.

3 Manitoba Center for Health Policy, Faculty of Medicine, University of Manitoba, Winnipeg, Manitoba, Canada.

Correspondence to: Dr Allen Kraut, Department of Community Health Sciences, University of Manitoba, S112-750 Bannatyne Avenue, Winnipeg, Manitoba R3E OW3, Canada. [E-mail: akraut@ms.umanitoba.ca] 
unemployment as they do not include persons who have stopped looking for work and have left the labor force or those who desire full-time work but are only working part-time (20). This later group can be referred to as being "underemployed" (20). The adverse effects of lack of full-time work may differ in groups of unemployed persons, those who have left the labor force due to an inability to find work or are only working parttime. We could locate no information on the possible association between working part-time and attempted suicide rates.

The objective of this study was to compare the relationships between unemployment, part-time work, nonlaborforce participation, and full-time work with attempted suicide after control for potential confounding factors. We hypothesized that attempted suicides would be least frequent in the full-time employed group and that the frequency would increase progressively in the part-time employed group and the unemployed group. We also hypothesized that the group of nonlaborforce participants would more frequently attempt suicide than the fully employed group.

\section{Subjects and methods}

\section{Sources of data}

This study is based on a unique research database created through the collaboration of Statistics Canada, the Government of Manitoba, and the University of Manitoba. This database combines longitudinal information on individual encounters with the Manitoba health care system over a 7-year period (1983-1990) with detailed information on social, economic, and occupational characteristics provided by a 5\% sample of Manitoba respondents on the census $2 \mathrm{~B}$ form in 1986. Twenty percent of the households in the province received the $2 \mathrm{~B}$ form. After persons who moved out of the province or who resided in institutions were excluded, the data set consisted of a fixed cohort of 43188 persons.

Residents of Manitoba are universally insured for medically necessary health care by a single payer agency, the Manitoba Health Services Insurance Plan (MHSIP). All computerized records of health care encounters contain unique personal identifiers that permit the creation of longitudinal individual histories of health care utilization (21). All but a small minority of physicians provide services on a fee-for-service basis. When submitting a service claim for reimbursement, physicians are required to provide the single diagnosis that is most responsible for the patient encounter. Diagnoses are recorded in the computerized medical-claims file at the third-digit level using the International Classifica- tion of Disease, Clinical Modification (ICD-9-CM) (22). Information on hospitalization is also captured by this system, with up to 16 hospital discharge diagnoses recorded on each hospital encounter. The hospitalization file codes diagnoses to the five-digit level in the ICD-9 system. E-codes, a supplemental classification of external causes of injury and poisonings that allows for the identification of suicide attempts, are used in the hospital data file.

Responses to the 1986 census 2B form included information on the level of attained education, sources and amounts of individual and household income, and selfreported occupation, industry and laborforce participation. In addition, information on sociodemographic variables such as gender, ethnicity, area of residence, and marital status were also collected. Additional information on the number of weeks worked and hours per week worked in 1985 were also recorded.

The study database was drawn using a multistage stratified design with each person being assigned a sample weight. The methodology used to link the records in the two data sources and create the study sample has been described previously $(23,24)$.

\section{Employment status}

Standard Statistics Canada definitions were used to determine the employment status of the participants in June 1986 (25). The standard definition assumes that all persons aged 15 years and older and not residing in institutions are potential laborforce participants. The analysis was limited to those of working age (15-64, years, $\mathrm{N}=27446$ ). Those who are not actively seeking work are not considered to be in the labor force $(\mathrm{N}=7019)$. Laborforce participants are either employed $(\mathrm{N}=18518)$ or unemployed ( $\mathrm{N}=1737)$. Part-time workers were identified as those employed at the time of the census but not in full-time work (more than 30 hours/week for more than 48 weeks per year) in 1985 , the year prior to the census. Of the employed workers, 8119 met the definition of part-time worker, leaving 10397 as full-time employed persons. The weighted unemployment rate of the sample was $6.3 \%$, which agreed closely with the official unemployment rate $(6.5 \%)$ at the time of the census (25).

\section{Identification of attempted and successful suicide cases}

From the health care utilization records, cases of attempted and successful suicide were identified as having met one of the following criteria: (i) hospitalization with an E-code diagnosis of suicide and self-inflicted injury (E950-59) or injury undetermined, whether accidental or purposely inflicted (E980-989 excluding 
988.8) according to the ninth revision of the International Classification of Diseases (ICD-9) between 1 April 1983 and 31 March 1990 and (ii) death between 3 June 1986, the date of the census, and 31 March 1990 and death certificate reporting suicide as the cause of death.

These definitions follow the usual practice in the epidemiology of suicide (2) and identify only serious suicide attempts and not self-harm gestures that are not attempts to end life. Although we did not specifically validate this definition of attempted suicide, claimsbased definitions of various diseases, including diabetes (26) and inflammatory bowel disease (27), have been validated in previous work through the use of the linked data. In our data set of working-age noninstitutionalized persons, 112 persons attempted suicide 126 times prior to the census, and 144 persons attempted suicide 158 times in the 3.5 years following the census. Of these attempts, 16 were successful.

\section{Identification of potential confounding variables}

Information was obtained from the census on potential confounding variables, including age, gender, household income, area of residence, education, marital status, ethnicity, prior mental health care, living with a full-time working person, and living in the same residence for 5 years. Aboriginal ethnicity was identified as of Inuit, North American Indian, or Metis heritage. History of treatment for a mental health disorder was defined as one or more hospital admissions or two or more physician contacts for the treatment of mental health conditions (ICD-9 290-319). Suicide attempts prior to the census were identified according to the aforementioned criteria. The given definition of part-time worker includes many persons who, for personal reasons, choose not to work full-time. Many of these people may reside with a person who is working full-time. Thus identifying people who live with a full-time employed person may help address this potential source of bias. Table 1 details the frequencies of the variables between persons that did and did not attempt suicide.

\section{Analysis}

Stepwise multiple logistic regression was used to determine the effects of age (15-24, 25-44, and 45-64 years), gender, educational status (less than grade 10, grade 1012 , some postsecondary schooling), area of residence (Winnipeg, non-Winnipeg urban, and rural), marital status (married and common law versus all other), ethnicity (aboriginal versus nonaboriginal), living with a fulltime employed person (yes, no), living in the same dwelling for the previous 5 years (yes, no), household income (continuous variable), previous mental health care (yes, no), suicide attempts from 1 April 1983 to 5 June 1986 (yes, no), and employment status on the likelihood of an individual attempting suicide following the census. The employment variables were divided into the following four mutually exclusive categories: full-time employed, part-time employed, unemployed, and not in the labor force. Full-time employed persons served as the reference category. The employment variables were forced into the model. Odds ratios (OR) with $95 \%$ confidence intervals $(95 \% \mathrm{CI})$ were used to approximate the risk ratios and are the measure of the association reported.

In an attempt to determine the effects of confounding, once the significant variables were identified in the model, they were entered one by one to see how they would influence the odds ratio of the association of the employment status variables with attempted suicide.

The analysis was repeated to compare the effects of unemployment with the effects of the other employment categories representing those who were not working

Table 1. Sociodemographic characteristics of persons attempting and not attempting suicide, Manitoba, Canada, 1986.

\begin{tabular}{lcc}
\hline & \multicolumn{2}{c}{ Attempted suicide } \\
\cline { 2 - 3 } Variable & $\begin{array}{c}\text { No } \\
(\mathrm{N}=27128) \\
(\%)\end{array}$ & $\begin{array}{c}\text { Yes } \\
(\mathrm{N}=144) \\
(\%)\end{array}$ \\
\hline Employment & & \\
$\quad$ Not in labor force & 23.3 & 34.5 \\
$\quad$ Unemployed & 5.4 & 17.3 \\
Employd part-time & 30.9 & 31.0 \\
$\quad$ Employd full-time & 40.4 & 17.2 \\
Age group & & \\
15-24 years & 23.1 & 36.1 \\
25-44 years & 46.8 & 44.5 \\
$\quad$ 45-64 years & 30.1 & 19.4 \\
Female & 50.7 & 50.7 \\
Married & 64.0 & 44.6 \\
Living with a full-ime employed person & 46.0 & 28.6 \\
Aboriginal ethnicity & 3.3 & 23.7 \\
Education & & \\
$\quad$ Less than grade 10 & 20.3 & 29.7 \\
$\quad$ Grade 10-12 & 38.3 & 39.2 \\
Some postsecondary schooling & 41.4 & 31.1 \\
Living in same dwelling as 5 years earlier & 58.1 & 41.2 \\
With mental health hospitalization ${ }^{c}$ & 1.6 & 15.0 \\
Two or more mental health ambulatory & 9.9 & 39.9 \\
Contacts ${ }^{c}$ & & \\
Suicide attempt ${ }^{c}$ & 0.3 & 6.9 \\
\hline
\end{tabular}

a Weighted number: 27785.51 for those with no suicide attenpts and 91.51 for those with suicide attempts.

b Mean 1985 household income CAD 38081 for those with no suicide attempts and CAD 27910 for those with suicide attempts.

c In the period from 1 April 1983 to 5 June 1986. 
full-time and to investigate for a potential "dose-response" relationship by looking at the number of weeks worked in 1985 as a predictor of future suicide attempts.

Stratified analyses were performed to identify differences in the subgroups. Comparisons were made for the odds ratios for attempted suicide for persons who did and did not live with a person who was employed full-time, had previous mental health problems, was young (age 14-25) versus others, aboriginal heritage versus all other, gender, and household income split at the median household income. These analyses controlled for all of the significant variables listed in table 2 with the exception of the stratifying variable when appropriate.

All information was stored in a SUN computer (Sun Microsystems, Mountain View, CA, USA). Normalized sample weights, where each person's sample weight was divided by the mean weight of the sample, were used in all the analyses. All the analyses were performed using SAS 6.12 (28).

Table 2. Predictors of attempted suicide in Manitoba, Canada, 1986-1990.

\begin{tabular}{lcc}
\hline Variable & Odds ratio & 95\% confidence interval \\
\hline Part-time work & 1.99 & $1.07-3.71$ \\
Out of the labor force & 2.11 & $1.12-3.97$ \\
Unemployment & 3.68 & $1.76-7.71$ \\
Married & 0.61 & $0.40-0.94$ \\
Aboriginal ethnicity $_{\text {Residential stability }}$ & 5.69 & $3.35-9.66$ \\
Mental health care hospitalization $^{\text {a }}$ & 0.59 & $0.39-0.91$ \\
Mental health ambulatory care $^{\text {a }}$ & 2.09 & $1.01-4.31$ \\
Suicide attempt $^{\text {a }}$ & 4.32 & $2.70-6.90$ \\
\hline
\end{tabular}

a In the period from 1 April 1983 to 5 June 1986.

\section{Ethics}

This linkage of the databases was approved by the ethics committees of Statistics Canada, the University of Manitoba and the Access and Confidentiality Committee of Manitoba Health. To ensure that there was no unintentional breach in confidentiality, the information in this manuscript was reviewed by the Health Information Privacy Committee of Manitoba Health.

\section{Role of the funding source}

No external funding was received for this project

\section{Results}

Table 2 shows the results of the stepwise multiple regression procedure. Aboriginal ethnicity, previous mental health care, and previous suicide attempts were all associated with attempted suicide. Residential stability and being married were protective. Being unemployed, working part-time, and being out of the labor force were all associated with attempted suicide. When the analysis was repeated comparing the unemployed group with the other groups who were not working full-time, the adjusted odds ratio for attempted suicide for the unemployed group was 1.65 (95\% CI 0.92-2.96).

Figure 1 shows the relative influence of the sequential addition of each significant variable on the association of the employment variables with suicidal behavior. The association between unemployment and attempted suicide appeared to be more strongly affected by potential confounding by variables other than parttime work or being out of the labor force.

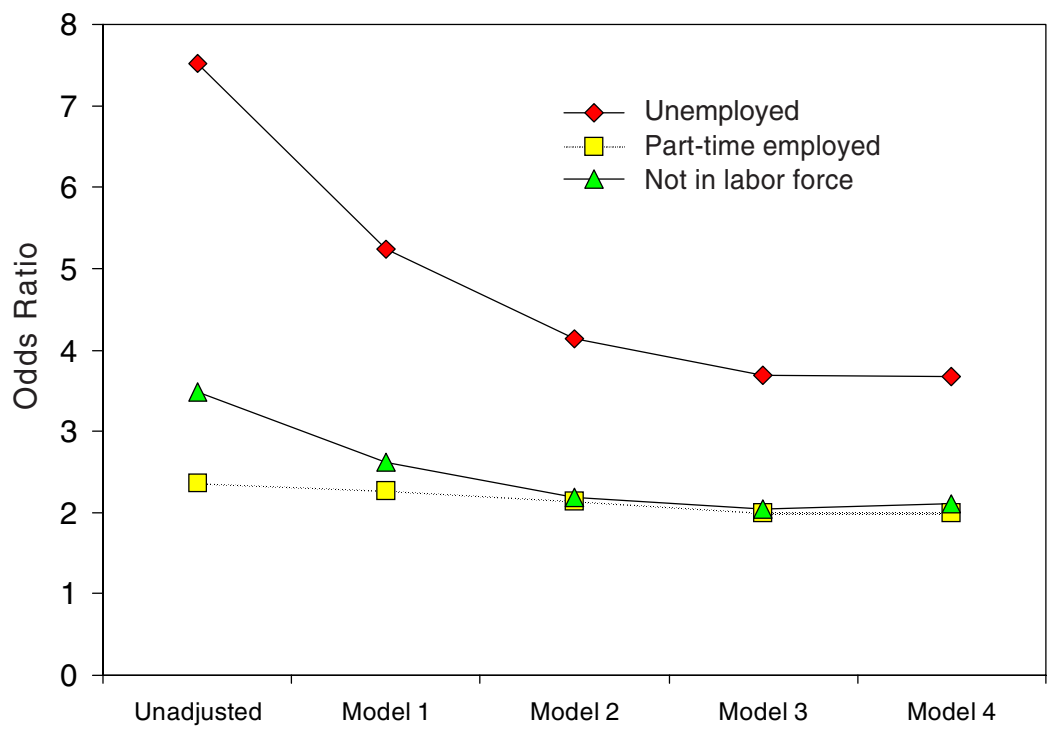

Figure 1. Effect of adjustment on the odds ratios for attempted suicide in the employment groups. Model 1 adjusts only for aboriginal ethnicity; model 2 adjusts for aboriginal ethnicity and prior mental health care or attempted suicide in the precensus period; model 3 adjusts for the variables in model 2 and marital status; model 4 adjusts for all the variables in model 3 and residing in the same dwelling for the previous 5 years. All the comparisons have been made with full-time employment. 
A model controlling for the significant variables in the stepwise regression, unemployment on the day of the census, and working less than 30 hours per week was used to investigate the association between weeks worked in 1985 and suicide attempts after the census. Working 52 weeks in 1985 was used as the reference category. In a comparison with the reference category, a dose-response relationship was observed with progressive increases in the reported odds ratios for working 26-51 weeks (OR 1.40, 95\% CI 0.67-2.90), working 125 weeks (OR 2.22, 95\% CI 1.05-4.70), and working zero weeks (OR 2.90, 95\% CI 1.04-8.09).

Stratified analyses were performed to identify the differences in the importance of the employment variables in the subgroups (table 3 ). Unemployment was uniformly associated with higher odds ratios for attempted suicide than with either part-time work or out of the labor force in all of the subgroups that were examined. Females appeared to have higher rates of attempted suicide than males in all of the employment categories as well. Stratification for variables such as living with a full-time employed person and income was performed to help identify groups of part-time employed persons and those out of the labor force who may have chosen not to work full-time. In these stratifications the groups with fewer resources, those not living with a full-time employed person, and those with lower incomes were at higher risk of attempted suicide.

\section{Discussion}

Our results show a strong association between unemployment and attempted suicide. They also illustrate that some of this association is due to confounding as the odds ratio fell from 7.5 (95\% CI 3.74-15.13) to 3.68 (95\% CI 1.76-7.71) after adjustment for potential confounding factors. Our findings are consistent with other work showing that unemployment is associated with both adverse mental health outcomes (10, 12-16, 29, 30) and suicide $(2,3,9)$. Our findings are unlikely to be due to recent mental health care or suicide attempts, ethnicity, education, or income, as we were able to control for these variables.

We identified higher adjusted odds ratios for unemployment than for both part-time work and being out of the labor force. When compared directly with the other causes of not working full-time, unemployment had an elevated odds ratio for attempted suicide (OR 1.65, 95\% CI 0.92-2.96). These findings are consistent with the state of unemployment causing more stress than parttime work or accepting the fact that work is not available and leaving the labor force.

An adjusted odds ratio of 3.68 and an unemployment rate of $6.6 \%$ allowed us to estimate a population attributable risk of approximately $15 \%$ for attempted suicide in relation to unemployment (31). This finding is similar to the results of Lewis \& Sloggett (2), who reported

Table 3. Influence of the employment variables on suicide behavior in Manitoba, Canada, in 1986-1990-results of the stratified analysis. ${ }^{a}(\mathrm{OR}=$ odds ratios, $95 \% \mathrm{Cl}=95 \%$ confidence interval)

\begin{tabular}{|c|c|c|c|c|c|c|}
\hline \multirow[t]{2}{*}{ Characteristic } & \multicolumn{2}{|c|}{ Unemployed } & \multicolumn{2}{|c|}{ Part-time employed } & \multicolumn{2}{|c|}{ Out of labor force } \\
\hline & $\mathrm{OR}^{\mathrm{b}}$ & $95 \% \mathrm{Cl}$ & $\mathrm{OR}^{\mathrm{b}}$ & $95 \% \mathrm{Cl}$ & $\mathrm{OR}^{\mathrm{b}}$ & $95 \% \mathrm{Cl}$ \\
\hline \multicolumn{7}{|c|}{ Living with a full-time employed person } \\
\hline Yes $(\mathrm{N}=33)$ & 1.60 & $0.38-6.81$ & 0.82 & $0.28-2.36$ & 1.26 & $0.46-3.44$ \\
\hline No $(N=111)$ & 5.34 & $2.13-13.4$ & 3.24 & $1.45-7.25$ & 2.98 & $1.29-6.86$ \\
\hline \multicolumn{7}{|c|}{ Mental health contacts or suicide attempts in period prior to census } \\
\hline Yes $(N=50)$ & 3.22 & $1.00-10.4$ & 2.38 & $0.91-6.23$ & 2.16 & $0.81-5.79$ \\
\hline No $(\mathrm{N}=94)$ & 4.54 & $1.79-11.5$ & 1.81 & $0.80-4.10$ & 2.23 & $0.98-5.08$ \\
\hline \multicolumn{7}{|l|}{ Age group } \\
\hline $15-24$ years $(\mathrm{N}=70)$ & 3.38 & $0.49-23.4$ & 2.73 & $0.48-16.6$ & 2.20 & $0.35-14.0$ \\
\hline 25-64 years $(\mathrm{N}=74)$ & 4.00 & $1.67-9.60$ & 2.02 & $0.98-4.15$ & 1.81 & $0.89-3.66$ \\
\hline \multicolumn{7}{|l|}{ Aboriginal ethnicity ${ }^{c}$} \\
\hline No $(\mathrm{N}=68)$ & 3.22 & $1.40-7.40$ & 1.82 & $0.96-3.44$ & 1.84 & $0.94-3.62$ \\
\hline Yes $(\mathrm{N}=76)$ & .. & .. & .. & .. & .. & .. \\
\hline \multicolumn{7}{|l|}{ Gender } \\
\hline Female $(\mathrm{N}=76)$ & 8.67 & $2.08-36.2$ & 4.12 & $1.09-15.6$ & 5.21 & $1.41-19.2$ \\
\hline Male $(\mathrm{N}=68)$ & 2.60 & $0.96-7.06$ & 1.60 & $0.74-3.45$ & 1.32 & $0.51-3.42$ \\
\hline \multicolumn{7}{|l|}{ Household income } \\
\hline Above median ( $\mathrm{N}=31)$ & 2.39 & $0.62-9.26$ & 1.26 & $0.47-3.42$ & 0.52 & $0.12-2.21$ \\
\hline Below median $(\mathrm{N}=113)$ & 4.55 & $1.76-11.7$ & 2.51 & $1.08-5.88$ & 3.01 & $1.31-6.96$ \\
\hline
\end{tabular}

a All the analyses controlled for the effect of age, ethnicity, marital status, aboriginal status, residential stability, mental health hospitalizations, ambulatory care contacts and precensus suicide attempts. Each employment group has been compared with the full-time employed group.

b Odds ratios adjusted for attempted suicide.

c There are no values for persons with aboriginal ethnicity as no full-time employed aboriginal person attempted suicide in the reference group. 
a suicide population attributable risk of $12.6 \%$ for unemployment among men aged 14-44 years in the United Kingdom.

Part-time work was also found to be associated with attempted suicide (adjusted OR 1.99, 95\% CI 1.073.71). Part-time work, underemployment for some persons, may place persons under stresses similar to being unemployed, although to a less extent. The subgroup analyses that were more likely to identify groups who would want to work full-time, persons who were not living with a full-time employed person, or persons having below the median household income showed elevated attempted suicide rates only in the groups at higher risk. This finding would be consistent with lack of fulltime employment putting persons at increased risk of attempted suicide.

Since some people choose to work part-time and would not be under such stress, our findings may underestimate the true effect of part-time work on suicide for those who want to work full-time but can only find part-time work. We have attempted to account for this source of bias by controlling for potential confounders and stratification. These maneuvers would reduce, but not eliminate, this source of bias. Since we found no other information examining the association between part-time work and attempted suicide, these results should be viewed as preliminary. Separating part-time workers into those who choose to work fewer hours and those who would rather work full-time would be an important point in future research in this area.

We have also demonstrated a dose-response relationship between working fewer weeks and attempted suicide. This finding is consistent with increasing difficulties due to a lack of employment pushing people towards attempting suicide.

People who were out of the labor force also had an elevated unadjusted and adjusted odds ratio of 3.48 (95\% CI 1.90-6.38) and 2.11 (95\% CI 1.12-3.97), respectively, for attempted suicide. People who are out of the labor force include homemakers, students, disabled persons, persons who do not want to or do not have to work, and those that have stopped looking for work due to an inability to find it. Because of the nature of the data set we could not separate this group into its various components. Stratification in this group (table 3) revealed findings similar to those of the part-time employed group, with higher odds ratios in the groups who did not live with a full-time employed person and who had lower than the median income, groups who would be more likely to need to work. People who were not in the work force and came from households with above the median income had a lower than expected attempted suicide rate (OR $0.52,95 \%$ CI $0.12-2.21$ ). This finding would be consistent with these people being at lower risk of attempted suicide, as they had less stress due to greater financial resources. In summary, all three groups of people who were not working full-time had an elevated likelihood of attempted suicide. This finding suggests that working full-time may be protective against attempted suicide.

The stratified analyses also showed increased rates of attempted suicide among females as compared with males. We are cautious in our interpretation of this finding, as, in the unadjusted data, women and men had similar attempted suicide rates and in the logistic regression gender was not found to be a significant predictor of attempted suicide. The stratified analysis result may have been influenced by the small number of suicide attempts among women in the reference category of fulltime employed persons.

The major limitation of our study was that we did not have access to individual data on some possible confounding variables, such as genetic factors, mental health problems prior to 3.5 years before the census, or other difficulties that may influence suicidal behavior. As well, administrative data may not correctly identify all people who would be considered by clinical criteria to have mental health conditions; therefore confounding by unrecognized mental health problems cannot be excluded. We also do not know the proportion of people working part-time or out of the labor force who were not working full-time by choice or because they could not find appropriate work. The groups of part-time workers and those out of the labor force include people who choose not to work full-time. This limitation leads to a dilution of the effect of lack of full-time employment on attempted suicide and leads to an underestimation of the true influence these variables have on attempted suicide. Our work was also limited by the lack of employment data for more than one point in time. Misclassification of the employment groupings would likely lead to an underestimation of the effect of unemployment on attempted suicide. Another potential limitation is that selection due to death by causes other than suicide may have influenced the results.

The major strengths of this study are that it was population-based, was able to control for a large number of known confounding factors, and was able to study the effects of underemployment on attempted suicide.

In summary, our data are consistent with unemployment leading to an increased risk of attempted suicide. Our findings that part-time work and being out of the labor force are also associated with attempted suicide even after adjustment for potential confounding factors and stratification are consistent with adverse health effects of underemployment and require verification in future work. Although the proportion of attempted suicide in the working-age population due to a lack of fulltime work may appear relatively small, this fraction may be more preventable than other causes of attempted 
suicide and could be decreased by social policies that limit "un" and underemployment.

\section{Acknowledgments}

This research was supported by the Manitoba Center for Health Policy.

\section{References}

1. Statistics Canada. Health indicators 1999 82-221-XCB. Ottawa (Canada): Statistics Canada; 1999.

2. Lewis G, Sloggett A. Suicide, deprivation, and unemployment: record linkage study. BMJ 1998;317:1283-6.

3. Platt S. Unemployment and suicidal behaviour: a review of the literature. Soc Sci Med 1984;19(2):93-115.

4. Crombie IK. Trends in suicide and unemployment in Scotland, 1976-86. BMJ 1989;298:782-4.

5. McLoone P. Suicide and deprivation in Scotland. BMJ 1996;312:543-4.

6. Beautrais AL, Joyce PR, Mulder, RT. Unemployment and serious suicide attempts. Psychol Med 1998;28:209-18.

7. Jones SC, Forster DP, Hassanyeh F. The role of unemployment in parasuicide. Psychol Med 1991;21:169-76.

8. Platt S, Micciolo R, Tansella M. Suicide and unemployment in Italy: description, analysis and interpretation of recent trends. Soc Sci Med 1992;34(11):1191-201.

9. Morrell S, Taylor R, Quine S, Kerr C. Suicide and unemployment in Australia 1907-1990. Soc Sci Med 1993;36(6): 749-56.

10. Lynch JW, Kaplan GA, Shema SJ. Cumulative impact of sustained economic hardship on physical, cognitive, psychological, and social functioning. N Engl J Med 1997;337: 1889-95.

11. Janlert U, Hammarstrom A. Alcohol consumption among unemployed youths: results from a prospective study. Br J Addict 1992;87:703-14.

12. Turner JB. Economic context and the health effects of unemployment. J Health Soc Behav 1995;36:213-29.

13. Lahelma E. Unemployment and mental well-being: elaboration of the relationship. Int J Health Serv 1992;22:261-74.

14. Frese M, Mohr G. Prolonged unemployment and depression in older workers: a longitudinal study of intervening variables. Soc Sci Med 1987;25:173-8.

15. Liira J, Leino-Arjas P. Predictors and consequences of unemployment in construction and forest work during a 5-year follow-up. Scand J Work Environ Health 1999;25:42-9.

16. Kraut A, Mustard C, Walld R, Tate R. Unemployment and health care utilization. Scand J Work Environ Health. 2000; 26:169-77

17. Valkonen T, Martikainen P. The association between unemployment and mortality: causation or selection? In: Lopez AD, Caselli G, Valkonen T, editors. Adult mortality in developed countries: from description to explanation. Oxford: Clarendon Press; 1995. p 201-22.

18. Montgomery SM, Bartley MJ, Cook DG, Wadsworth ME. Health and social precursors of unemployment in young men in Great Britain. J Epidemiol Community Health 1996; 50(4):415-22.

19. Arrow J. Estimating the influence of health as a risk factor on unemployment: a survival analysis of employment durations for workers surveyed in the German socio-economic panel (1984-1990). Soc Sci Med 1996;42:1651-9.

20. Jin RL, Shah CP, Svoboda TJ. The impact of unemployment on health: a review of the evidence. Can Med Assoc J 1995; 153(5):529-40.

21. Roos LL, Mustard CA, Nicol P, McLerran DF, Malenka DJ, Young TK, et al. Registries and administrative data: organization and accuracy. Med Care 1993;31:201-12.

22. Department of Health, Education and Welfare (DHEW). International classification of diseases, 9th revision (clinical modifications). Ann Arbor (MI): Public Health Service; 1987.

23. David P, Berthelot JM, Mustard C. Linking survey and administrative data to study the determinants of health. Ottawa: Social and Economic Studies Division, Statistics Canada; 1992.

24. Houle C, Berthelot JM, David P, Mustard CA, Roos LL, Wolfson MC. Project on matching census 1986 database and Manitoba health care files: private households component. Ottawa: Analytic Studies Branch, Statistics Canada; 1996. Research papers series, no 91.

25. Statistics Canada. Historical labour force statistics. Ottawa: Statistics Canada; 1997. Catalogue no 71-201-xpb.

26. Kraut A, Walld R, Tate R, Mustard C. Impact of diabetes on employment and income in Manitoba, Canada. Diabetes Care 2001;24:64-8.

27. Bernstein CN, Kraut A, Blanchard JF, Rawsthrone P, Yu N, Walld R. The relationship between inflammatory bowel disease and socioeconomic variables. Am J Gastroenterol 2001; 96:2117-25.

28. SAS Institute. SAS software release 6.12. Cary (NC): SAS Institute; 1996.

29. Linn MW, Sandifer R, Stein S. Effects of unemployment of mental and physical health. Am J Public Health 1985;75(5): 502-6.

30. Kammerling R, O'Connor S. Unemployment rate as predictor of rate of psychiatric admission BMJ 1993;307:1536-9.

31. Kahn HA, Sempos CT. Statistical methods in epidemiology. New York (NY): Oxford University Press; 1989.

Received for publication: 22 April 2002 